European Association for the

Development of Renewable Energies,

Environment and Power Quality
International Conference on Renewable Energies and Power Quality (ICREPQ'09)

Valencia (Spain), 15th to 17th April, 2009

\title{
Supply security and the reliability of the Spanish generator system in the next two decades based on the costs of fossil fuels and nuclear option.
}

\author{
F. Delgado, A. Ortiz, C. J. Renedo, S. Pérez, M. Mañana \\ Department of Electrical and Energy Engineering \\ E.T.S.I.I., Cantabria University \\ Avenida de Castros, 39005 Santander (Spain) \\ Phone: +34-942-201376, Fax: +34-942-201385 \\ E-mail: delgadof@unican.es
}

\begin{abstract}
The supply security of the primary energy sources (coal, natural gas, enriched uranium...) and the reliability of the system in terms of the oscillations of the frequency and voltage are two aspects to assess in the Generation Expansion Planning. In this article, for the first criterion, the evolution of vulnerability and degree of independence of the generator system with respect to primary energy sources has been assessed by the indexes of Shannon-Weiner and energy independence, respectively. For the second approach, the evolution of the reserve margin by means the coverage index and the progression of the inertia and regulation capacity by means of its percentage regarding the total installed capacity. These four indexes have been applied on the obtained results of a stochastic lineal model developed with the software GAMS. In this model the nuclear technology has been considered as generation option in several scenarios of costs of the fossil fuels, coal and natural gas. Also, two of clean coal technologies with greater possibility of putting into service have been taken into account. The final conclusion would be that each technology carries out several functions in the generator system but not all them. That is, a generator system should have the greatest possible number of types of generation to be reliable and have supply security.
\end{abstract}

\section{Key words}

Generation expansion planning, nuclear energy, fossil fuels, clean coal, supply security, reliability of the system.

\section{Introduction}

In Spain, in the last decade, the growth in electricity demand was roughly a $4.5 \%$ annually, although in some years it reached almost $7 \%$ (6.8\% in 2003). Also, the forecasts of demand of capacity and energy estimate that this growth will continue, but at a lower rate: $2.5 \%$ annually until 2020 and $1.5 \%$ for the period 2021-2030, approximately.

Numerous aspects must be considered in the Generation Expansion Planning (GEP) to cover that growing demand. The supply security would be one of them.
Spanish electric generation is based, in a very important way, in the fossil fuels, coal and the natural gas mainly. Nowadays, $50 \%$ of the demand, approximately, is covered by the classic thermal power stations of coal (PCP), natural gas combined cycle (NGCC), and fueloil/gas power plants. And the trend seems to be maintained or increased in an important way. Moreover, Spain has no primary resources, natural gas and coal, mainly.

Another aspect to consider in the GEP is the reliability of the generator system. The determination of the supply security, meaning the probability of certain magnitudes (reserve margin, voltage and frequency) are outside the limits [1], would be a way to analyze it.

In recent years, the reserve margin has had a falling trend. On the other hand, the forecasts of next years that are established in [2] are based on the assumption of the maintenance in service of the number of current nuclear groups. The Coverage Index (CI) can be used to determine the reserve margin (See table 01).

Table 01. Coverage Index

\begin{tabular}{|c|c|c|c|}
\hline Date & CI & Date & CI \\
\hline $\begin{array}{c}\text { 09-01-02 } \\
19-20 \mathrm{~h}\end{array}$ & 1.13 & $\begin{array}{c}30-01-06 \\
19-20 \mathrm{~h}\end{array}$ & 1.09 \\
\hline $\begin{array}{c}18-02-03 \\
19-20 \mathrm{~h}\end{array}$ & 1.19 & $2007 *$ & 1.15 \\
\hline $\begin{array}{c}02-03-04 \\
20-21 \mathrm{~h}\end{array}$ & 1.15 & $2008 * *$ & 1.12 \\
\hline $\begin{array}{c}27-01-05 \\
19-20 \mathrm{~h}\end{array}$ & 1.12 & $2011 * *$ & 1.10 \\
\hline
\end{tabular}

This index has had a falling trend due to a combination of two factors: high growth of the peak demand, [3], and an increase in the relative weight of the Energies of Special Regime $^{1}$ in the generation mix; mainly, the large growth

\footnotetext{
The special regime of the electric sector includes the following generation activities: wind, photovoltaic, biomass, minihydroelectric... among renewable energies, and
} 
of Wind Generation (WG) that possesses a high unavailability index. On the other hand, the forecasts that are established in [2] for the CI of coming years are based on the assumption of the number of current nuclear groups being kept in service.

The other two magnitudes to control, voltage and frequency, must have values within preset margins, [4]. Both magnitudes should be as stable as possible so that the electric system can meet the demand within appropriate conditions of quality and continuity. It is necessary that a part of the generation is carried out at every moment by means of large rotating machines. Such machines are capable of maintaining the generationdemand balance in the presence of perturbations (increase/decrease of the demand, disconnection of a power station due to failure, etc.), due to its good regulation of capacity, both inertial and automatic. The turbines used in hydroelectric generation, and in classic and nuclear thermal generation possess these regulation characteristics $^{2},[5]$.

In Spain, in the past, the generator system has always operated with hydroelectric turbines and with classic and nuclear thermal technologies as base generation, providing a significant proportion of the generated total energy. Therefore, the peninsular Spanish electric system has been one of the most reliable in the world regarding voltage and frequency. Nevertheless, due to the important growth of the generation with renewable energies and NGCC and the withdrawal of classic and nuclear thermal capacity, the percentage is in continuous decline (See Table 02, author's elaboration based on data from [3].

Table 02. Percentage of Inertial and Regulation Capacity [\%]

\begin{tabular}{|c|c|c|c|c|c|}
\hline & 2003 & 2004 & 2005 & 2006 & 2007 \\
\hline \% de I.R.C. & 75,5 & 69,7 & 60,7 & 57,8 & 56,5 \\
\hline
\end{tabular}

Many questions arise from the above: How the supply security evolution will be? And the reliability of the generator system? An electric system with little classic and nuclear thermal generation, and based mainly on renewable energies and combined cycle, is it reliable? Will the energy dependence of the Spanish electric system increase? or will it diminish?

To answer these questions and otherwise, a model of the Spanish generator system by stochastic linear programming has been developed whose objective is to obtain the generation mix that be able to cover the demand in the period 2013-3032 with the minimum cost. The analysis of the influence of the nuclear option on

cogeneration, urban waste, industrial and agricultural wastes among the non-renewable. This type of energy receives incentives to attract private initiative, since they require heavy investment in technology development and construction and to bring the power plants into service, with long paying-off periods.

2 The primary, secondary and tertiary regulations could be carried out by other technologies, but they are not used for that purpose for many reasons. For example, the NGCC would be able to provide secondary regulation, but they are not usually used with that purpose due to loss of efficiency. system reliability and supply security, for different scenarios of costs of fossil fuels, is carried out.

\section{Model, hypothesis, baseline data, cost scenarios and applied indexes}

The model has been developed through the programming language specific to the GAMS application, using the CPLEX optimizer to resolve it.

The objective is to minimize the current value of the system generator annual costs, this being subject to a number of both technical and economic restrictions.

Two cases have been analyzed, nuclear and non-nuclear, for several scenarios of variable costs of generation by assigning probabilities to two basic scenarios denominated High priority gas and High priority coal

The baseline data and cost scenarios are taken from numerous sources. Cite just two: [6] and [7].

Indexes of Shannon-Wiener and Energy Independence (EI) have been applied on the results of the model with the aim of analyzing the supply security. Also, the calculation of the Coverage Index and the Percentage of Inertial and Regulation Capacity (PIRC) has allowed analyzing the reliability of the system (See Table 03).

Table 03. Indexes of supply security and reliability of the system

\begin{tabular}{|c|c|c|c|}
\hline \multicolumn{4}{|c|}{ Vulnerability Indexes } \\
\hline \multicolumn{2}{|c|}{ Shannon-Weaver } & \multicolumn{2}{|c|}{ Energy Independence } \\
\hline \multicolumn{2}{|c|}{$H=\sum_{i=1}^{I}-p_{i} \times \ln p_{i}$} & \multirow{5}{*}{\multicolumn{2}{|c|}{$E I=\frac{d p}{t p e c} \times 100$}} \\
\hline & Diversity & & \\
\hline $\mathrm{H}<1$ & Small & & \\
\hline $1<\mathrm{H}<2$ & Intermediate & & \\
\hline $\mathrm{H}>2$ & High & & \\
\hline \multicolumn{4}{|c|}{ Reliability Indexes } \\
\hline \multicolumn{2}{|c|}{ Coverage Index } & \multicolumn{2}{|c|}{$\begin{array}{c}\% \text { of Inertial and } \\
\text { Regulation Capacity }\end{array}$} \\
\hline \multicolumn{2}{|c|}{$C I=\frac{a c}{d c} \times 100$} & \multicolumn{2}{|c|}{$P I R C=\frac{i r c}{t c} x 100$} \\
\hline & Coverage & & Stability \\
\hline $\mathrm{CI}<1.1$ & Small & $\mathrm{PIRC}<50$ & Unstable \\
\hline $\mathrm{CI}=1.1$ & Intermediate & $50<$ PIRC $<60$ & Stable \\
\hline $\mathrm{CI}>1.1$ & High & PIRC $>60$ & Very stable \\
\hline
\end{tabular}

The first index measures the diversity for the type of fuel used in the generation mix. This index is used in ecology and related sciences to measure the biodiversity from the proportion (pi) of the individuals of different species regarding the total, (See Table 3 ). It is able to measure two of the three basic characteristics of the diversity, the variety and the balance, [8].

The species-fuel analogy has been carried out for its use in the measurement of the diversity of the generator system. Note that this index is a simplified measure of the diversity. Its results depend on the grade of 
independence between the different categories established depending on the fuel [9]. For simplicity's sake, this article assumes there to be total independence between them (See Table 04).

Table 04. Categories established depending on the fuel

\begin{tabular}{|c|c|}
\hline Category & Fuel \\
\hline NGCC y GT & Natural Gas \\
\hline NPP & Uranium \\
\hline PCP, PCP w/CCS and IGCC w/CCS & Coal \\
\hline WG & Wind \\
\hline HP & Water \\
\hline SRE & Water, Light, biomass... \\
\hline
\end{tabular}

The higher the value of this index, the greater the diversity of the system, as shown in the table 03 . A value of this index below one indicates a highly concentrated system that depends on one or two fuels and, is therefore, very vulnerable to any interruption in supply of these energy sources; the analyzed system is diversified if the value is superior to two, with numerous energy sources, none of them with a dominant role, indicating the opposite of the above.

The second indicator measures the independence of the generator system on fuel imports. According to [10], Energy Independence (EI) is expressed as the proportion of domestic production, (dp), with regard to the total primary energy consumption (tpec), (See Table 03). Obviously, the higher the percentage, the greater the degree of independence. The following simplifying suppositions have been kept in mind for its calculation:

$\checkmark$ Negligible self-supply degree with autochthonous coal and natural gas. For both fuels, the reasons are different:

- Initially, from 2013 on, it is assumed that subsidies ${ }^{3}$ to domestic coal will no longer be kept up, because of the liberalizing trend which European Union is seeking for gas and electricity markets. Therefore, if only a purely economic criterion is considered, the fuel used by PCP, $\mathrm{PCP}$ w/CCS and IGCC w/CCS would be imported coal.

- The Spanish reserves of natural gas are negligible.

$\checkmark$ The self-supply degree of nuclear fuel is $100 \%$, despite the fact that Spain does not have the primary resource, uranium. The reason for such a degree of selfsupply is that the Spanish government founded the company ENUSA in the 70s with public funds, in order to ensure the supply of enriched uranium to all the Spanish nuclear power stations. On account of this, this company has financial shareholdings and industrial alliances of an international character that allows it to participate in all phases of the nuclear fuel cycle, from extraction to production.

\footnotetext{
${ }^{3}$ From this date, in the European Union, only those mines that are considered as strategic reserves for supply security can be
}

The reliability of the generator system obtained from the planning has been valued by some authors by means of the determination of its reserve margin. They assume that the probability of demand coverage is high if the obtained generation mix has a relatively high reserve margin, [11].

The CI determines the reserve margin by means of the relationship between the available capacity of the generator system (ac) and the demanded capacity (dc), at the time of peak demand (see Table 03). Traditionally, to manage the coverage of demand for the system in an extreme situation appropriately, the desirable minimum value that has been considered for the $\mathrm{CI}$ is 1.1 ; below this value, in case of any unforeseen event (e.g. unscheduled shutdown of a plant), coverage would not be assured. In fact, in the Spanish electricity regulations, the annual quantity of the incentive to investment in longterm capacity perceived by each new generation facility depends on that value: a bigger incentive is received if the value of the index is bigger than the aforementioned quantity than if it is smaller, [12].

One way to indirectly control system stability, and thus its reliability, would be the measurement of the generation percentage with hydroelectric, classic and nuclear thermal technologies (irc) with respect to the total generation (tc), in the three characteristic demand blocks, peak, plain and valley. This index has been denominated Percentage of Inertial and Regulation Capacity (PIRC) (See Table 03).

According to [5], taking into account the availability of hydropower in Spain, between $50 \%-60 \%$ of the generation in service must be achieved by means of hydraulic and steam turbines due to regulation requirements. Thus, if the percentage of generation with these technologies was below the aforementioned range the system could become unstable. And this instability will be much bigger, the higher the proportion of nonmanageable energy ${ }^{4}$ that is operating at any time. This is due to deficiencies in the response to fluctuations in the system of this type of energy.

\section{Results and conclusions}

The results of the analyzed period 2013-2032 have been grouped into five-year periods in order to carry out a more precise analysis.

It should be mentioned that there are preset investments in generation equipment (wind farms, NGCC, photovoltaic generation...) that are independent of those calculated by the model throughout the analyzed period.

For the nuclear case, shown in Figure 01, in the three scenarios and throughout the four periods of five years,

exploited, and will be eligible for state subsidisation. All remaining mines must close.

4 Predictable but not programmable energy, such as wind and photovoltaic generation. 
the installation would be almost exclusively of nuclear capacity.

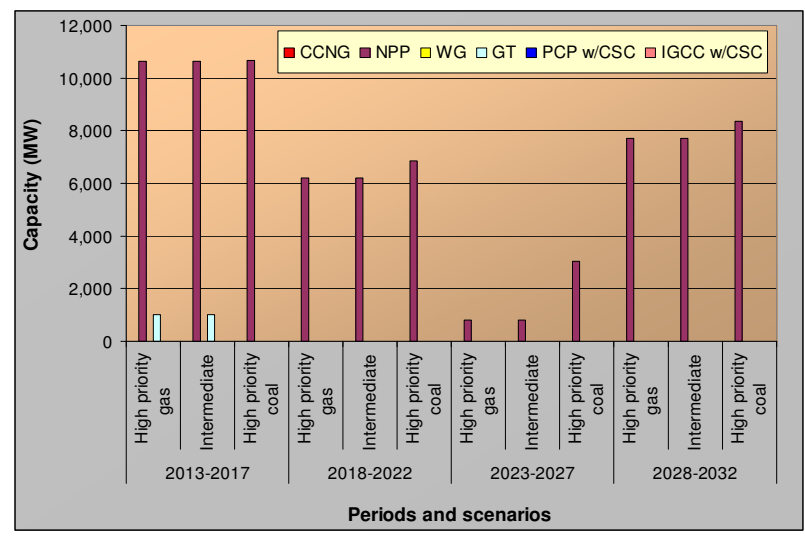

Figure 01. Capacity to be installed defined by technology and a five year period in each scenario. Nuclear case.

For the non-nuclear case, shown in Figure 02, in the three scenarios and over the four periods of five years, large amounts of wind power would be put into service in addition to the existing investment forecasts for this type of technology. Also, the NGCC and PCP with $\mathrm{CO}_{2}$ Capture and Storage (PCP w/CCS) technologies would contribute capacity to the system in the second and third five year period.

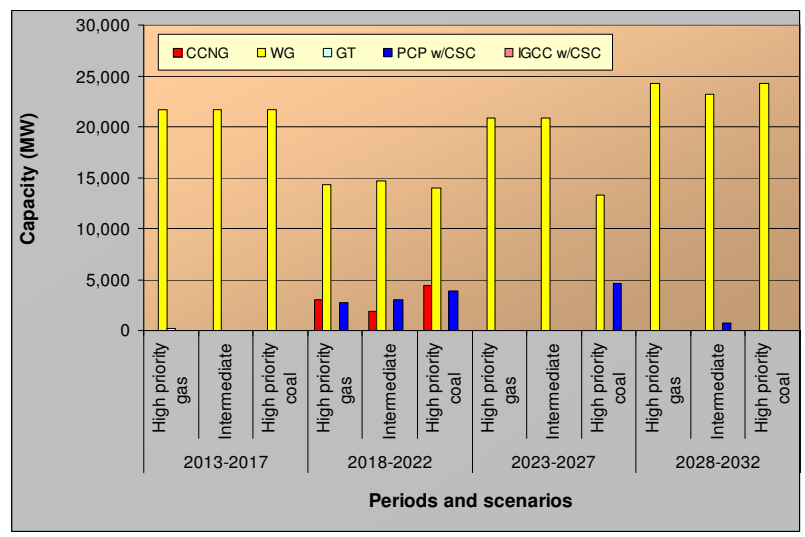

Figure 02. Capacity to be installed defined by technology and a five year period in each scenario. Non-nuclear case.

Figure 03 shows that for the nuclear case, an EI close to $90 \%$ would be reached at the beginning of the 20 's, getting similar percentages or even higher at the end of the analyzed period. On the other hand, for the nonnuclear case, the EI would increase gradually, reaching the maximum values in the last five year period, among $80-85 \%$.

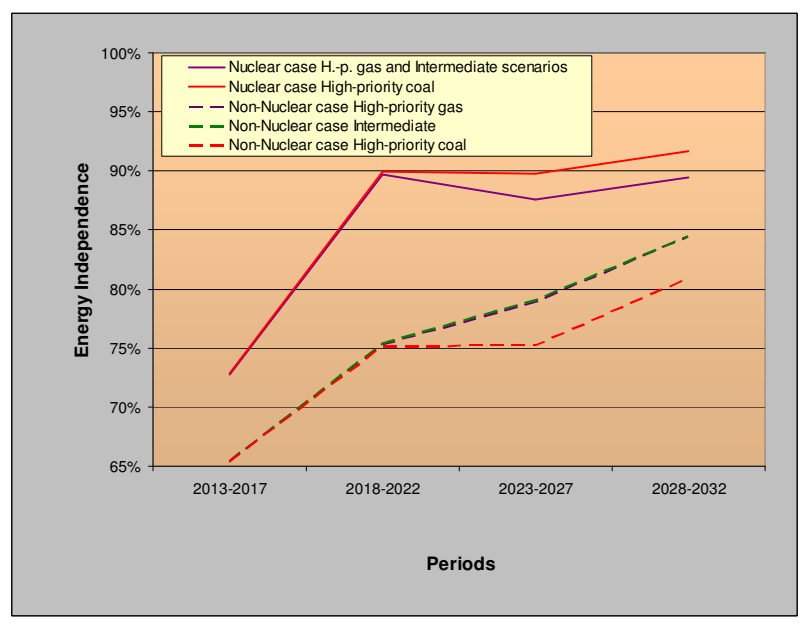

Figure 03. EI evolution in both cases under all the scenarios

Figure 04 shows that the energy diversification would be intermediate, with an index of Shannon-Wiener among 1 and 2, and falling, in both cases and under all the scenarios.

The CI evolution that is shown in Figure 5 is declining, being below $5 \%$ at the end of the analyzed period, in all cases except one.

Figure 06 shows that The PIRC evolution is completely different in both cases. In the nuclear case, this index is continuously above $60 \%$, assuring with it the stability of the system. Meanwhile, in the non-nuclear case, the decrease of this percentage is continued, reached values below $30 \%$ in the last five years period.

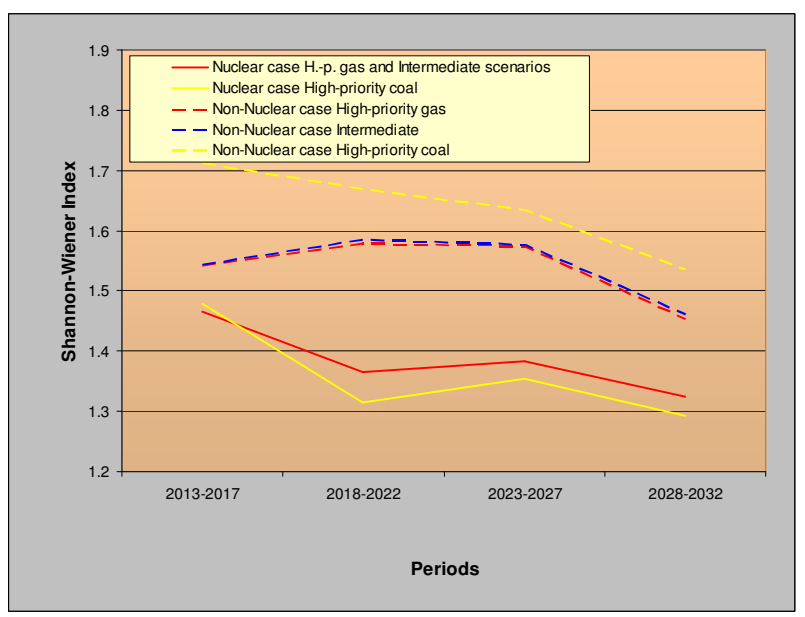

Figure 04. Shannon-Wiener index evolution in both cases under all the scenarios 


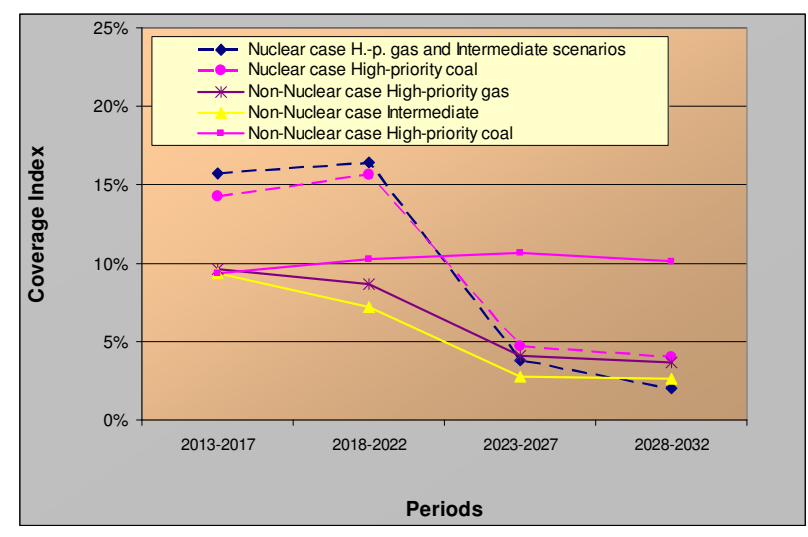

Figure 05. Coverage index evolution in both cases under all the scenarios

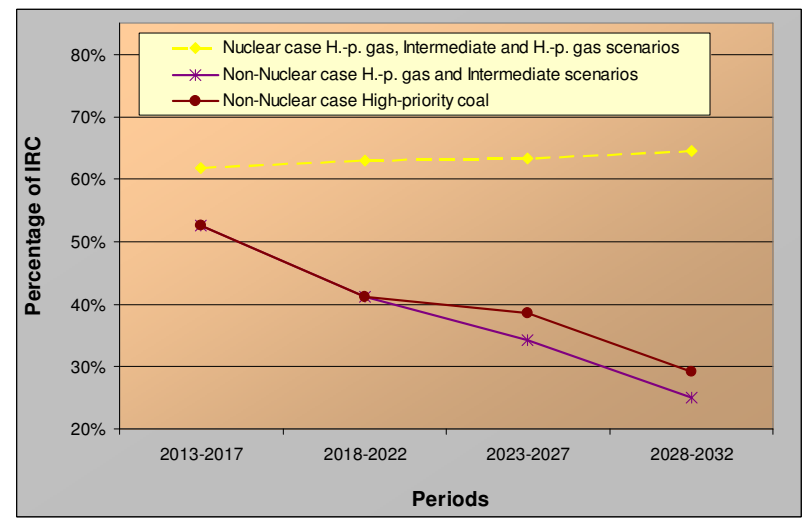

Figure 06. PIRC evolution in both cases under all the scenarios for the demand period valley

In both cases, the energy independence that is obtained at the end of the analyzed period is high. This independence would be bigger if the nuclear option was chosen, reaching maximum values a decade earlier than in the other case. The dependence of the fossil fuels would also decrease and, mainly, of the natural gas whose deposits are in politically unstable countries. For both cases, this independence would be increased if the autochthonous resources of coal were exploited.

The vulnerability of the Spanish generator system would be smaller if the renewable energy were developed jointly with the technologies of clean coal and combined cycle that if the nuclear option was chosen. However, in one case as in the other, the diversification decays with time because the generator system has been designed being based on a reduced number of technologies. The development of a generation mix where all technologies are present -renewable energy, combined cycle, clean coal, nuclear...- and none of them with a predominant role is necessary to prevent the above from happening.

The CI could reach values below 1.1, jeopardizing the coverage of demand in a period of peak demand. Furthermore, if the companies don't consider costeffective investment in peak equipment (Gas Turbines, mainly), in spite of the payment for the availability service, would be necessary a vertical displacement of the semi-base equipment ( $\mathrm{PCP}$ w/CSC and NGCC) to cover part or the entirety of the high part of the load curve. Therefore, with the purpose of assuring the coverage of the maximum demand, it would be necessary the development of a generation mix which, while maintaining the existent nuclear equipment, capacity of NGCC and PCP w/CCS complemented with renewable energy was installed.

If the nuclear option was chosen, the stability of the generator system would be assured because the ability of development of this technology exists [13]. Instead, CCS systems are in early stages of development, with the many uncertainties involved: political, technological, economic, etc, [14].

As a final conclusion, it is necessary to stress that no technological option is the magical cure to the problem of the coverage of the electric demand. The technology that is suitable from all the points of view doesn't exist. Each one carries out some function inside the generator system, not all of them: the nuclear generation and the renewable energy will assure the supply. The technologies of NGCC and PCP w/CSC will allow the coverage of the peak demand and the second one, together with the nuclear technology, the stability of the system. Finally, the equilibrated development of all technologies will give place to a less vulnerable generator system due to that greater diversification.

\section{References}

[1] R. Billinton and R. N. Allan, Reliability Evaluation of Power Systems, 2a edición, Ed.Springer, 1996, pp. 514.

[2] MITYC, "Planning of the electricity and gas sectors 2008$2016 "$, in 2008, in spanish.

[3] REE, "Reports 1995-2007. The spanish electric system", in 2007, in spanish.

[4] F. Alvarado and S. Oren, "Transmission system operation and interconnection", In: National transmission grid studyissue paper.

[5] C. Martínez Vidal and V. Casajús Díaz, "Generation mix in the spanish electricity system on the horizon 2030", in 2007, in spanish.

[6] UNESA, "Prospective of electric generation 2030", in 2007, in spanish.

[7] MITYC, "Planning of the electricity and gas sectors 20022011. revision 2005-2011", in 2006, in spanish.

[8] A. Stirling. (1998, On the economics and analysis of diversity. SPRU Electronic working paper series 28

[9] A. Stirling, "Diversity and ignorance in electricity supply investment addressing the solution rather than the problem", Energy Policy, vol. 22, pp. 195-216, 1994.

[10] WEC, "Europe's vulnerability to energy crises", 2008.

[11] D. Kottick, M. Blau and Y. Frank, "Reliability of supply to consumers as a function of the installed generation reserve margin", Electric Power Systems Research, vol. 33, pp. 63-67, 4, 1995.

[12] MITYC. Order ITC/2794/2007, revision of the electric rates, 27-09-2007.

[13] G. H. Marcus, "Innovative Nuclear Energy Systems and the Future of Nuclear Power", Progress in Nuclear Energy, vol. 50, pp. 92-96, 0. 2008.

[14] VGB, " $\mathrm{CO}_{2}$ Capture and storage, a VGB report on the state of the art", in 2004. 